\title{
Synthesis of Non-hydrate Iron Oleate for Eco-friendly Production of Monodispersed Iron Oxide Nanoparticles
}

\author{
Do Kyung Kim* and Jae Won Lee**; \\ *Department of Anatomy, College of Medicine, Konyang University, Daejeon 35365, Korea \\ **Department of Material Science and Engineering, College of Aviation, Jungwon University, Goesan 28024, Korea
}

(Received October 12, 2018; Revised October 29, 2018; Accepted October 30, 2018)

\begin{abstract}
In this work, we describe a novel and simple technique to produce non-hydrate surfactant complexes for the formation of highly crystalline fatty acid modified SPIONs by thermolysis of iron oleate (FeOl) complexes in a non-coordinating solvent. FeOl complexes were prepared by direct coordination of iron ions and carboxylic acid; thus, we could control the stoichiometric composition of the precursor by changing the molar ratio of fatty acid and metal ions. The discrete thermal behaviors and chemical coordination of the intermediate non-hydrated $\mathrm{FeOl}$ were studied by thermo-analytic techniques including differential scanning calorimetry, thermal gravimetric analysis, and Fourier transform infrared spectroscopy.
\end{abstract}

Key words : Oleic acid, Iron oxide, Nanoparticles, Thermal decomposition, Superparamagnetic

\section{Introduction}

$\mathbf{R}$ ecently, superparamagnetic iron oxide nanoparticles (SPIONs) have been the focus of extensive attention because such nanoparticles can be easily manipulated or transported by applying an external magnetic field gradient. ${ }^{1)}$ SPIONs hold enormous potential for applications in nanomedicine such as drug delivery, ${ }^{2)}$ hyperthermia, ${ }^{3)}$ and as magnetic resonance (MR) contrast agents ${ }^{4,5)}$ due to their outstanding magnetic and physiochemical properties, passive/active target specificity, biodegradability, and biocompatibility.

Various synthetic techniques have been reported to produce SPIONs, including thermal decomposition of organometallic precursors, ${ }^{6,7)}$ co-precipitation, ${ }^{8,9)}$ inert gas condensation, nanoemulsion, ${ }^{10)}$ magnetobacteria, ${ }^{11)}$ or laser pyrolysis. ${ }^{12)}$ The controlled chemical co-precipitation method is a commonly used method to synthesize clinically approved dextran coated iron oxide nanoparticles (Feri$\left.\operatorname{dex}^{\circledR}\right) .{ }^{13)}$ Co-precipitation of $\mathrm{Fe}^{2+}$ and $\mathrm{Fe}^{3+}$ under alkali conditions is required to prevent the oxidation of $\mathrm{Fe}^{2+}$ and to avoid the phase transition from magnetite to maghemite; therefore, it is quite vital that the reaction should be performed in an inert atmosphere, which can be done by directly flowing an inert gas into the solution during coprecipitation of the metal ions. It is already well reported that magnetite nanoparticles are easily oxidized and changed to maghemite in the presence of oxygen, such as dissolved oxygen dispersed in an aqueous phase or when exposed to

\footnotetext{
${ }^{\dagger}$ Corresponding author: Jae Won Lee

E-mail : jaeonelee@jwu.ac.kr

Tel : +82-43-830-8629 Fax : +82-43-830-9679
}

air. The process of co-precipitation involves an initial nucleation stage for the formation of a new phase, i.e., a phase transition from liquid to solid, followed by crystal growth as the solutes spontaneously assemble on the surface of the nucleus of particles. Several factors, including $\mathrm{pH}$, reaction time and temperature, and concentration of iron salts, can influence the co-precipitation process such that these reaction parameters can be altered in order to tune the properties of the resulting SPIONs. The synthesis of SPIONs by the thermolysis of an iron oleate $(\mathrm{FeOl})$ complex has attracted significant attention compared to other methods, such as hydrothermal and other organic-phase syntheses, due to its applicability to mass production and use of inexpensive and nontoxic metal salts such as iron (III) chloride $\left(\mathrm{FeCl}_{3}\right)$ and sodium oleate as reactants. Moreover, thermal decomposition of the $\mathrm{FeOl}$ complex can produce nanoparticles with different shapes, such as spherical, cubic, and frame shaped with different sizes ranging from 8.5 to 25 $\mathrm{nm}$. FeOl prepared by the conventional method is in a hydrate form and this synthesis process, including purification, is quite complicated and time consuming. Particularly, the $\mathrm{FeOl}$ is quite problematic to control because it is a sticky, viscous solid. This tar-like state makes it difficult to accurately weigh out stoichiometric compositions of precursors, which is one of the most important parameters to control in order to tune the diameter and homogeneity of the particles.

Here, we report on a simple and eco-friendly technique to produce non-hydrate $\mathrm{FeOl}$ complexes for the formation of highly crystalline fatty acid modified SPIONs by thermolysis of $\mathrm{FeOl}$ complexes in a non-coordinating solvent. FeOl complexes were prepared by direct coordination of iron ions and carboxylic acid; thus, we could control the stoichiomet- 
ric compositions of precursors by manipulating the molar ratio of fatty acid and metal ions. To identify the formation of $\mathrm{FeOl}$ complexes and SPIONs by heating, thermal analysis techniques were used to interpret the possible thermal decomposition mechanism for non-hydrate $\mathrm{FeOl}$ complexes. The thermolysis of $\mathrm{FeOl}$ starts with the splitting of a coordinating bond between a metal ion and an organic molecule, and the thermolysis temperature can serve as an indicator of the strength of the chemical bond. The thermolysis of $\mathrm{FeOl}$ involves the liberation of metal ions from carboxylic acid. As a result, monitoring the thermal properties of $\mathrm{FeOl}$ will provide some insight into the mechanism of thermal decomposition of metal-fatty acid complexes.

\section{Experimental Procedure}

\subsection{Materials}

Iron nitrate nonahydrate $\left(\mathrm{Fe}\left(\mathrm{NO}_{3}\right)_{3} \cdot 9 \mathrm{H}_{2} \mathrm{O}\right)$, cis-9-octadecenoic acid $\left(\mathrm{OA}, \mathrm{CH}_{3}\left(\mathrm{CH}_{2}\right)_{7} \mathrm{CH}=\mathrm{CH}\left(\mathrm{CH}_{2}\right)_{7} \mathrm{COOH}, 90.0 \%\right)$, hexane (99.0), ethanol (95\%), and 1-octadecene $\left(\mathrm{CH}_{3}\left(\mathrm{CH}_{2}\right)_{15} \mathrm{CH}\right.$ $=\mathrm{CH}_{2}$, ODE, 90.0\%) were obtained from Sigma-Aldrich.

\subsection{Synthesis}

Non-hydrated $\mathrm{FeOl}$ was prepared by direct reaction of a fatty acid with a metal salt at elevated temperatures. Briefly, $0.4 \mathrm{~g}$ of $\mathrm{Fe}\left(\mathrm{NO}_{3}\right)_{3} \cdot 9 \mathrm{H}_{2} \mathrm{O}$ was firstly mixed with a variable amount of $\mathrm{OA}$ in a three-neck flask. A proportional-integral-derivative (PID) controller was used to control the heating mantle. The temperature was increased to $110^{\circ} \mathrm{C}$ to eliminate any physically adsorbed water and byproduct, $\mathrm{HNO}_{3}$. During the heating, the solution colour changed from yellow to reddish brown. The temperature of the solution was decreased to $25^{\circ} \mathrm{C}$ and samples were collected for analysis.

Next, $1 \mathrm{mmol}(0.4 \mathrm{~g})$ of $\mathrm{Fe}\left(\mathrm{NO}_{3}\right)_{3} \cdot 9 \mathrm{H}_{2} \mathrm{O}$ and $1-5 \mathrm{mmol}$ of OA were dissolved in $5 \mathrm{~mL}$ of ODE. When the amount of $\mathrm{OA}$ is increased, the non-hydrated $\mathrm{FeOl}$ complexes tend to form a more tacky liquid; FeOl-14 and FeOl-15 are in a viscous, reddish brown phase. The solution was heated to $110^{\circ} \mathrm{C}$ for $2 \mathrm{~h}$ to remove the physically adsorbed water and nitric acid. After $30 \mathrm{~min}$, an air condenser was connected for refluxing. The reaction mixture was then heated to $320^{\circ} \mathrm{C}$ for $30 \mathrm{~min}$ with a heating rate of $3.3^{\circ} \mathrm{C} / \mathrm{min}$ under stirring. The color of the reactant changed from reddish brown to black. The fatty acid-coated SPIONs were dissolved in $10 \mathrm{~mL}$ hexane, precipitated by adding $20 \mathrm{~mL}$ ethanol, and centrifuged at $10,000 \mathrm{rpm}$ for $20 \mathrm{~min}$. The washing procedure was repeated 10 times and the fatty acid-coated SPIONs were re-dispersed in $10 \mathrm{~mL}$ hexane, forming an extremely stable ferrofluid. The resulting fatty acid-coated SPIONs are denoted as N1X53 (X=1, 2, 3, 4, 5). For example, N1253 implies fatty acid-coated SPIONs synthesized with $1 \mathrm{mmol} \mathrm{Fe}\left(\mathrm{NO}_{3}\right)_{3} \cdot 9 \mathrm{H}_{2} \mathrm{O}$ and $2 \mathrm{mmol} \mathrm{OA}$ in $5 \mathrm{~mL}$ of ODE after reacting for $30 \mathrm{~min}$ at $320^{\circ} \mathrm{C}$.

\subsection{Characterization}

The size and morphology of the nanoparticles were examined using two transmission electron microscopes, model JEOL $2100 \mathrm{~F}(200 \mathrm{kV})$ and 1230 (120 kV, Japan). The physical sizes of the iron oxide cores were measured on the JEOL $2100 \mathrm{~F}(200 \mathrm{kV})$, while both core and shell structures were observed using the JEOL $1230(120 \mathrm{kV})$. The average sizes were calculated by fitting the experimental results to a lognormal distribution function: ${ }^{14}$

$$
f\left(D_{p}\right)=\frac{1}{\sqrt{2 \pi} D_{p} \omega_{p}} \exp \left(-\frac{\left(\operatorname{In} D_{p}-\operatorname{In} D_{p}^{0}\right)^{2}}{2 \omega_{p}^{2}}\right)
$$

where $D_{p}$ is the mean of the diameters of the particles and $\omega_{\mathrm{P}}$ is the standard deviation around $\mathrm{InD}_{\mathrm{p}}^{0}$.

The mean diameter $\left(\mathrm{D}_{\mathrm{p}}\right)$ can be written as:

$$
D_{P}=D_{P}^{0} \exp \left(\omega_{p}^{2} / 2\right)
$$

And the standard deviation $\left(\sigma_{\mathrm{p}}\right)$ of the mean diameter can be written as:

$$
\sigma_{P}=D_{P}^{0}\left[\exp \left(2 \omega_{p}^{2}\right)-\exp \left(\omega_{p}^{2}\right)\right]^{1 / 2}
$$

Fourier transform infrared (FTIR) spectra were recorded using an Alpha FTIR spectrometer equipped with Diamond ATR (Bruker Optics). The samples were vacuum dried at $50^{\circ} \mathrm{C}$ for $24 \mathrm{~h}$ and crushed into fine powder for measurement. Spectra were recorded with a resolution of $1 \mathrm{~cm}^{-1}$ in the range of $500-4,000 \mathrm{~cm}^{-1}$.

Thermal gravimetric analysis (TGA), differential scanning calorimetry (DSC), and differential thermal analysis (DTA) analysis were carried out using a Q600 simultaneous DSC-DTA-TGA system from TA Instruments.

\section{Results and Discussion}

Figure 1 shows a schematic illustration of the fabrication process and thermal decomposition of iron(III) oleate complexes leading to monodispersed SPIONs: (a) dissolution of iron(III) nitrate salts in oleic acid; (b) formation of iron(III) oleate complexes at $120^{\circ} \mathrm{C}$ and unreacted $\mathrm{OA}$ dimerizing with oleate ligands via hydrophobic interactions; (c) breakdown of the hydrophobic interactions between free $\mathrm{OA}$ and oleate ligands in the $\mathrm{FeOl}$ structure at $\sim 180^{\circ} \mathrm{C}$; (d) decomposition of oleate ligands from the $\mathrm{FeOl}$ and formation of metastable nuclei at $200 \sim 250^{\circ} \mathrm{C}$; (e) complete removal of the residual oleate molecules from $\mathrm{FeOl}$ leading to growth of SPIONs above $320^{\circ} \mathrm{C}$. The structural influences of different concentrations of $\mathrm{OA}$ were studied for the coordination of non-hydrated FeOl. Fig. 2 presents FTIR spectra of nonhydrated $\mathrm{FeOl}$ synthesized by varying the ratio of $\mathrm{Fe}\left(\mathrm{NO}_{3}\right)_{3}$ and $\mathrm{OA}$ from $1 / 1$ to $1 / 5$. In the spectrum of pure OA, two bands appeared at 2,925 and $2,852 \mathrm{~cm}^{-1}$ which are due to the symmetrical and asymmetrical $-\mathrm{CH}_{2}$ stretching modes. There is a small peak at $3,012 \mathrm{~cm}^{-1}$ that can be assigned to $v(\mathrm{C}-\mathrm{H})$ of the $\mathrm{C}-\mathrm{H}$ bond that is adjacent to the cis $\mathrm{C}=\mathrm{C}$ bond. ${ }^{15)}$ A very shallow shoulder appeared at $2,960 \mathrm{~cm}^{-1}$ 

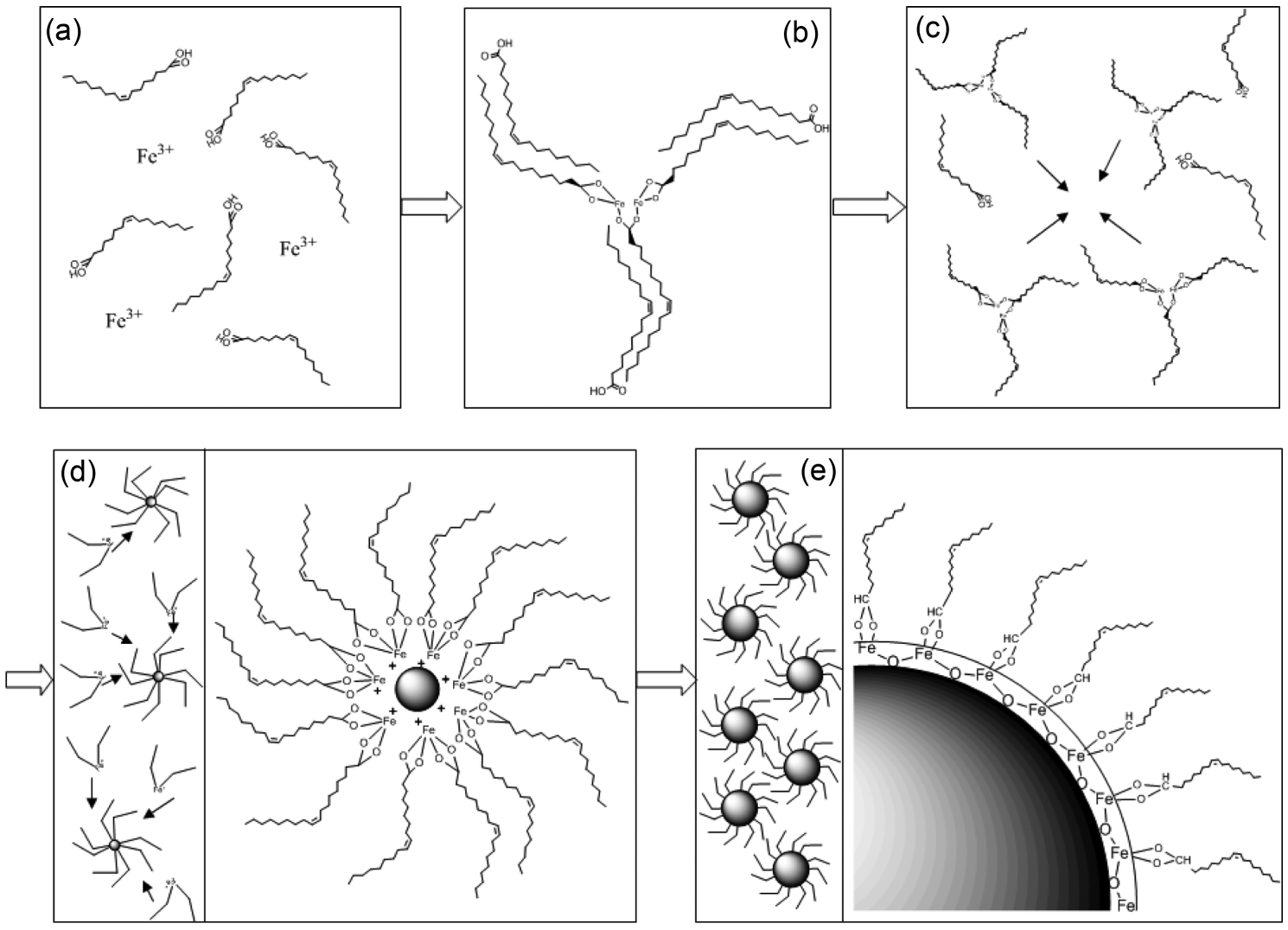

Fig. 1. Schematic illustration of the fabrication process and thermal decomposition of iron(III) oleate complexes leading to monodispersed SPIONs.

and was assigned to the asymmetrical $-\mathrm{CH}_{3}$ vibration mode. ${ }^{15)}$ The peaks at 1,456 and $934 \mathrm{~cm}^{-1}$ were assigned to $\mathrm{O}-\mathrm{H}$ in-plane and out-of-plane bending, respectively. ${ }^{16)}$ The intense band observed at $1,709 \mathrm{~cm}^{-1}$ was attributed to the $v(\mathrm{C}=\mathrm{O})$ of the carboxyl group. ${ }^{16,17)}$

Compared to pure OA, several different peaks appeared

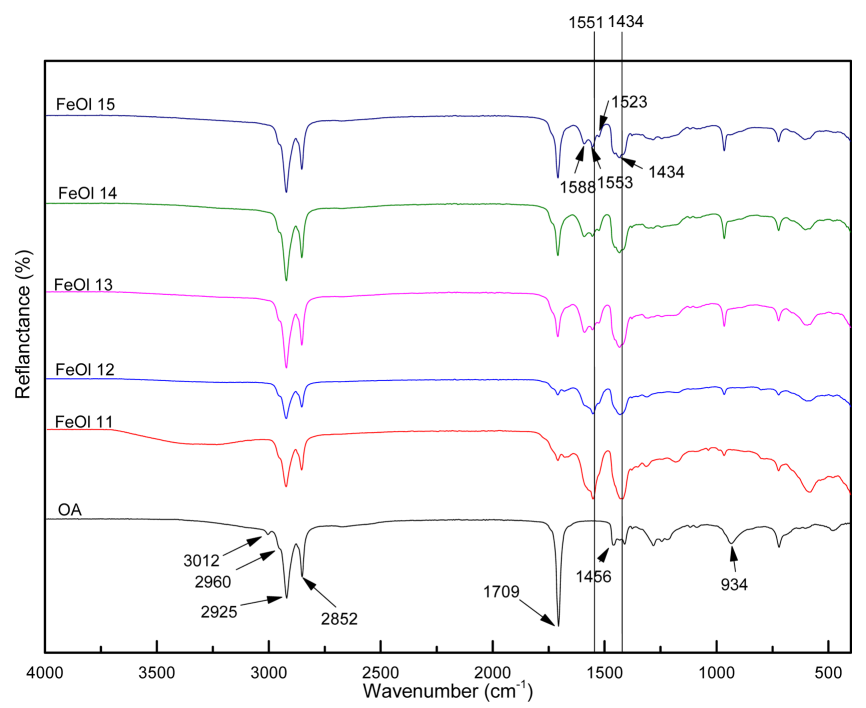

Fig. 2. The FTIR spectra of FeOl-1X, where X (OA/iron(III) molar ratio) $=1,2,3,4,5$, and pure $\mathrm{OA}$ from wavenumber $4,000 \mathrm{~cm}^{-1}$ to $500 \mathrm{~cm}^{-1}$. in the range of $1,650-1,500 \mathrm{~cm}^{-1}$ in all the case of nonhydrated $\mathrm{FeOl}$ due to freshly formed metal carboxylate bonds. A sharp peak at $1,434 \mathrm{~cm}^{-1}$ was also attributed to the vibration of metal carboxylate bonds. Peaks at 1,588, 1,553 , and $1,523 \mathrm{~cm}^{-1}$ were attributed to $v_{\mathrm{a}}\left(\mathrm{COO}^{-}\right)$of $\mathrm{FeOl}-$ 13,14 , and 15, among which the peak at $1,553 \mathrm{~cm}^{-1}$ had the strongest intensity. However, in FeOl-11 and 12, the peak was too weak to identify. The amplitude of the characteristic peak of unreacted OA at $1,709 \mathrm{~cm}^{-1}$ increased as the molar ratio of $\mathrm{Fe}(\mathrm{III}) / \mathrm{OA}$ was increased, with $\mathrm{FeOl}-15$ showing the highest intensity of the $1,709 \mathrm{~cm}^{-1}$ band, which can be explained by an increasing amount of unreacted OA. In FeOl-11 and 12, distinguished peaks appear at 1,551 $\mathrm{cm}^{-1}$ and $1,434 \mathrm{~cm}^{-1}$, which can be assigned to asymmetrical and symmetrical carboxylate vibrations, respectively, giving a $\Delta=117 \mathrm{~cm}^{-1}$, indicating that only the bidentate mode exists in these $\mathrm{FeOl}$ complexes. With increased OA concentrations, other asymmetric vibration bands of metal carboxylate appeared at $1,588 \mathrm{~cm}^{-1}$ and $1,523 \mathrm{~cm}^{-1}$, resulting in novel $\Delta=154$ and $89 \mathrm{~cm}^{-1}$. Therefore, in FeOl-13, 14, and 15, the hydrogen of the carboxylic acid binds to Fe ions in both bridging and bidentate forms.

In the spectrum of FeOl-14, two $-\mathrm{CH}_{2}$ bands $(2,925$ and $\left.2,852 \mathrm{~cm}^{-1}\right)$ and $\mathrm{a}-\mathrm{CH}_{3}$ band $\left(2,960 \mathrm{~cm}^{-1}\right)$ were observed at the same position as in the spectrum of pure OA. However, the peak at $3,012 \mathrm{~cm}^{-1}$ was not observed in the spectrum of FeOl-14, possibly because the cis $\mathrm{C}=\mathrm{C}$ was converted into 
trans $\mathrm{C}=\mathrm{C}$. Mossoba et al. reviewed FTIR methodologies for detection of trans- fatty acids in which bands at 965$975 \mathrm{~cm}^{-1}$ were also used to differentiate cis and trans substituted fatty acid and esters. ${ }^{18)}$ A new peak appeared at $965 \mathrm{~cm}^{-1}$ in the spectrum of $\mathrm{FeOl}-14$ due to the presence of trans $\mathrm{C}=\mathrm{C}$ bonds. Apparently, the $\mathrm{C}=\mathrm{C}$ bond of the $\mathrm{OA}$ was converted to a trans- configuration during the coordination reaction.

There is a very strong peak at $1,709 \mathrm{~cm}^{-1}$ in the FTIR spectrum of $\mathrm{OA}$, so it is more sensible to assign this peak to the $v(\mathrm{C}=\mathrm{O})$ stretching mode of free OA. Whereas no 1,709 $\mathrm{cm}^{-1}$ peak was observed in the spectrum of FeOl-14 because unreacted OA was removed during the ethanol wash. The intensity of $\mathrm{O}-\mathrm{H}$ bond out-of-plane and in-plane bands (1,456 and $934 \mathrm{~cm}^{-1}$ respectively) in the spectrum of FeOl14 were dramatically reduced and even difficult to distinguish, possibly due to the reduced amount of free OA in the specimen. In the range of $1,650-1,500 \mathrm{~cm}^{-1}$, a number of peaks were attributed to Fe carboxylate bands, as previously reported by Hyeon et al. ${ }^{19)}$ Three bands at 1,588, 1,553 , and $1,523 \mathrm{~cm}^{-1}$ are due to asymmetrical carboxylate vibrations, whereas the strong band appearing at 1,436 $\mathrm{cm}^{-1}$ is due to symmetrical carboxylate vibration. ${ }^{20)}$ The chemical coordination of $\mathrm{FeOl}$ can be identified based on the location and separation of asymmetrical and symmetrical iron carboxylate peaks, denoted as the splitting amount $\Delta .{ }^{17)}$ For $\Delta>200 \mathrm{~cm}^{-1}$, a unidentate mode can be expected, for $110 \mathrm{~cm}^{-1}<\Delta<200 \mathrm{~cm}^{-1}$ it is a bridging mode, and for $\Delta$ $<110 \mathrm{~cm}^{-1}$ it is a bidentate mode. The four coordinating modes between a metal ion and carboxyl groups are schematically illustrated in Fig. 3.

For FeOl-14, the variances between distinctive bands within the $v\left(\mathrm{COO}^{-}\right)$were 152,117 , and $87 \mathrm{~cm}^{-1}$, showing bidentate and bridging modes. Whereas, in $\mathrm{FeOl}-14$, the peaks appearing at 1,553 and $1,523 \mathrm{~cm}^{-1}$ correspond to asymmetrical vibrations, and the strong peak at $1,436 \mathrm{~cm}^{-1}$ can be assigned to a symmetrical vibration.

The thermal behavior of $\mathrm{OA}$ and non-hydrated $\mathrm{FeOl}$ was measured by thermal analysis. Fig. 4 shows the TGA, DSC, and DTA curves for the decomposition of pure OA up to $600^{\circ} \mathrm{C}$. The DSC and DTA curves exhibit very similar

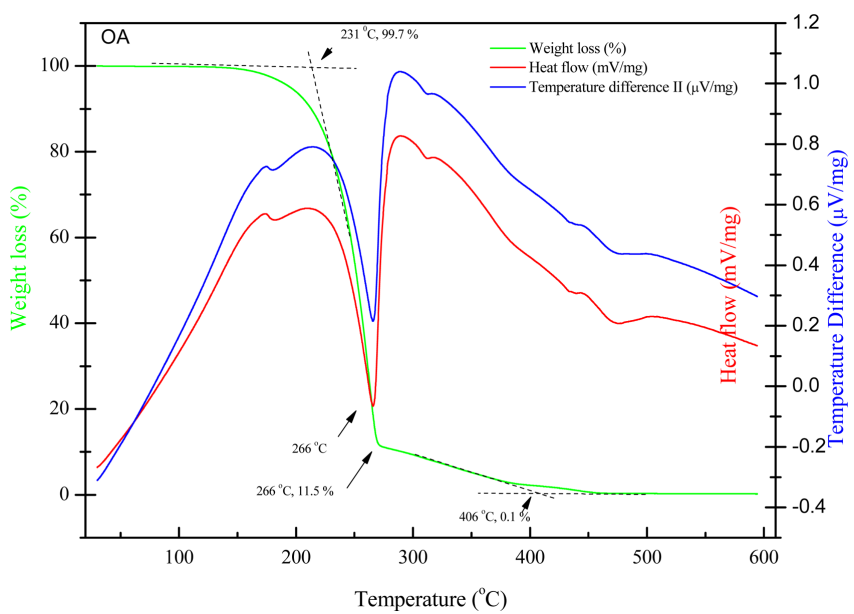

Fig. 4. TGA/DSC/DTA profiles of pure $\mathrm{OA}$ as a function of temperature from $30^{\circ} \mathrm{C}$ to $400^{\circ} \mathrm{C}$, with a heating rate of $10^{\circ} \mathrm{C} / \mathrm{min}$ and $\mathrm{N}_{2}$ protection gas at flow rate of 100 $\mathrm{mL} / \mathrm{min}$.

shapes, since both techniques are concerned with energy changes of the materials undergoing physical and/or chemical changes. The first exothermic transition peak appeared at $174^{\circ} \mathrm{C}$ without significant weight loss in the TGA curve, possibly due to the dissociation of the dimerized cis-9-octadecenoic acid. There is an eminent exothermic peak at $265^{\circ} \mathrm{C}$ suggesting thermal decomposition of OA, which is in good agreement with the literature. ${ }^{20,21)}$ Correspondingly, there is a sharp weight loss of $88.2 \%$ in this temperature range, the on-set temperature of thermolysis of $\mathrm{OA}$ is $231^{\circ} \mathrm{C}$, as shown in the TGA curve, and the mass loss decreased to $11.5 \%$ at $266^{\circ} \mathrm{C}$, indicating that the most of the cis-9-octadecenoic acid has been decomposed to $\mathrm{CO}$, $\mathrm{CO}_{2}, \mathrm{H}_{2} \mathrm{O}, \mathrm{H}_{2}$, ketones, esters, and hydrocarbons with different chain lengths. ${ }^{22}$ ) The mass percentage is further decreased to $0.1 \%$ at $406^{\circ} \mathrm{C}$ indicating that the decomposition of OA is complete.

The solid waxy forms of non-hydrated FeOl complexes were studied by thermal analysis to investigate the reaction mechanism for the formation of nanoparticles. Based on FTIR data, non-hydrated $\mathrm{FeOl}$ has a combination of

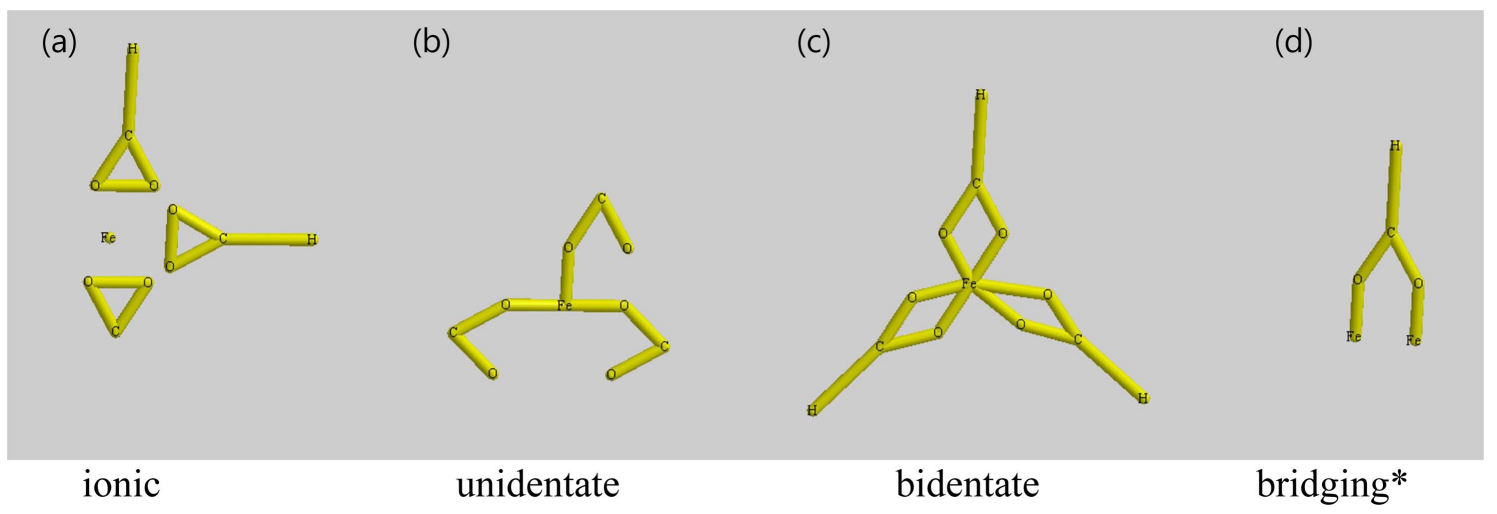

Fig. 3. The four different coordination modes between metal Fe ions and carboxyl groups: (a) ionic, (b) unidentate, (c) bidentate, and (d) bridging. ${ }^{17)} *$ The other two-valent Fe state is not shown in the scheme for simplicity. 
(a)

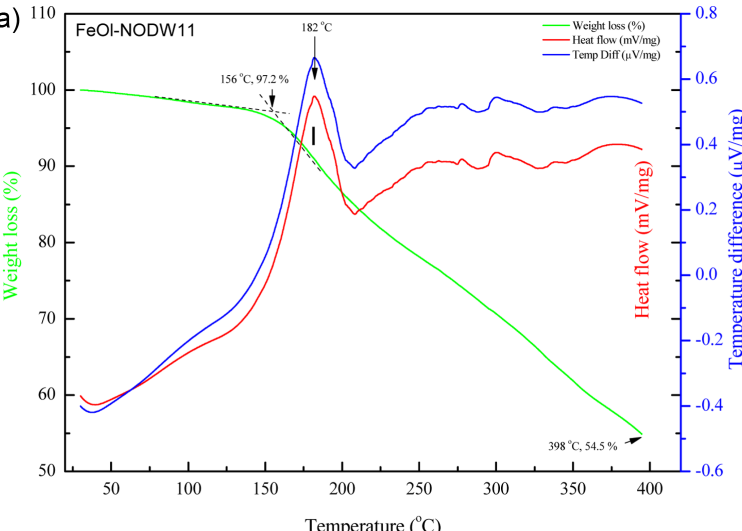

(c)

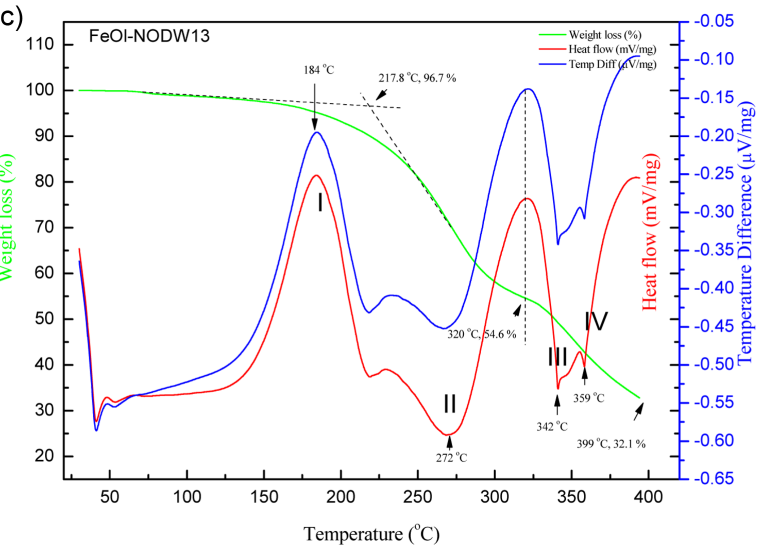

(e)

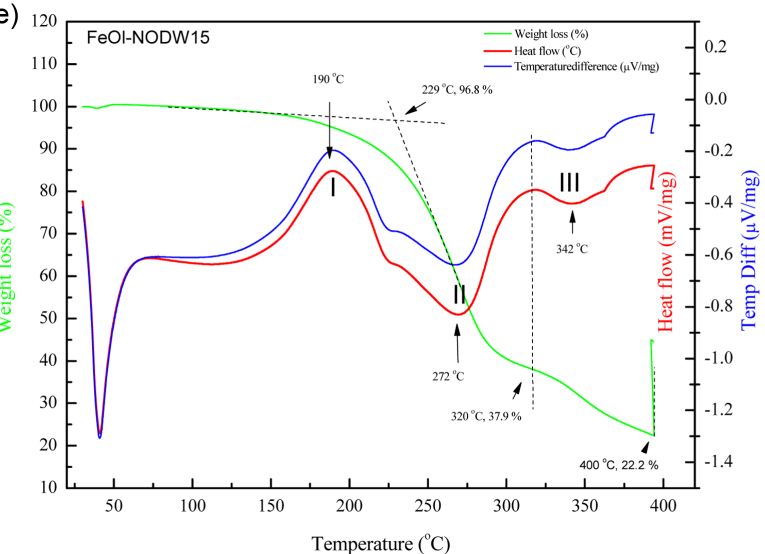

(b)

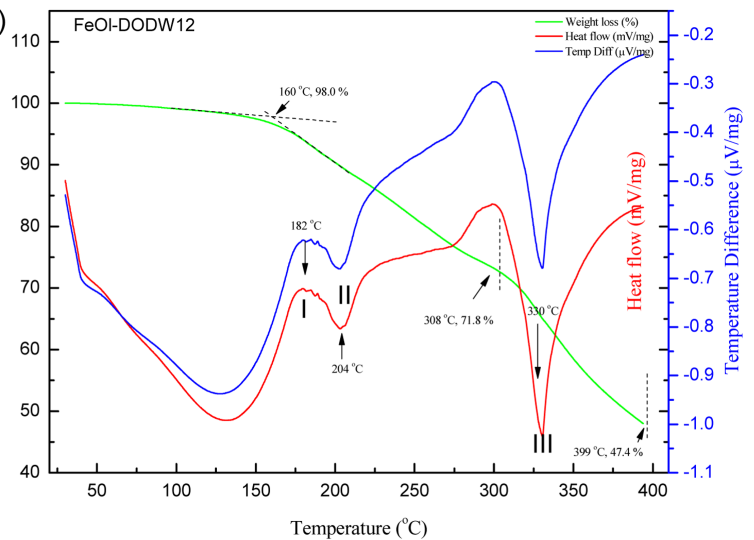

(d)

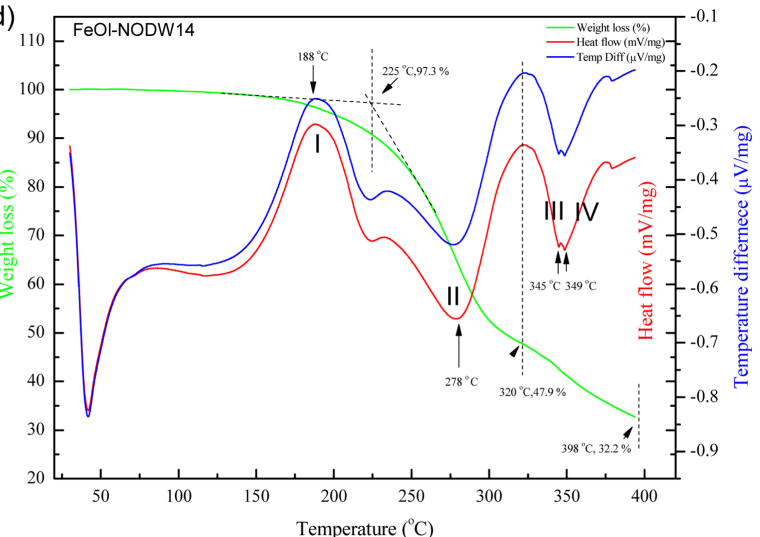

Fig. 5. TGA/DSC/DTA profiles of FeOl-NODW1X $(\mathrm{X}=1,2,3,4,5)$ as a function of temperature from $30^{\circ} \mathrm{C}$ to $400^{\circ} \mathrm{C}$, with a heating rate of $10^{\circ} \mathrm{C} / \mathrm{min}$ and $\mathrm{N}_{2}$ protection gas at flow rate of $100 \mathrm{~mL} / \mathrm{min}$.

excess cis-9-octadecenoic acid and $\mathrm{FeOl}$ with different chemical coordination states. Fig. 5 shows the TGA, DSC, and DTA profiles of $\mathrm{FeOl}-1 \mathrm{X}(\mathrm{X}=1,2,3,4,5)$ from $30^{\circ} \mathrm{C}$ to $400^{\circ} \mathrm{C}$. The first transition of hydrated $\mathrm{FeOl}$ samples has been reported at $132^{\circ} \mathrm{C}$ coming from the chemically absorbed water, ${ }^{17}$ ) while no such endothermic peak was observed from any of the non-hydrated FeOl-1X samples. The nonappearance of this peak is a complementary indication supporting the conclusion of the FTIR investigation that no water molecules were incorporated into the non-hydrated FeOl-1X, as shown in Fig. 5(a). The first exothermic transi- tion (I) of non-hydrated $\mathrm{FeOl}$ appeared at $179-190^{\circ} \mathrm{C}$ in all samples, which can be assigned to the breakdown of the hydrophobic interactions between hydrocarbon tails of unreacted $\mathrm{OA}$ and oleate ligands in the $\mathrm{FeOl}$ structures, because there is no corresponding significant weight loss in the TGA curves. With an increasing molar ratio of cis-9-octadecenoic acid to Fe ions, the exothermic peak was found to be slightly increased, indicating stronger association of oleate ligands and free cis-9-octadecenoic acid. The TGA results show good agreement with the endothermic peak in Fig. 5(b). 
In FeOl-11, no significant second transition was observed, indicating that nucleation of FeOl-11 happens over a broad range of temperature resulting in inhomogeneous particle sizes and shapes which is consistent with the TEM results. In FeOl-12, an endothermic peak (II) appeared at $204^{\circ} \mathrm{C}$, whereas in FeOl-13, 14, and 15, transition II happened at $272^{\circ} \mathrm{C}, 278^{\circ} \mathrm{C}$, and $270^{\circ} \mathrm{C}$ respectively. The second transition (II) peak which appears around $200-280^{\circ} \mathrm{C}$ can be attributed to the decomposition of free cis-9-octadecenoic acid or cis-9-octadecenoic acid weakly bonded to Fe atoms in the $\mathrm{FeOl}$ structure and the formation of metastable nuclei, because it matches the thermal decomposition of pure cis-9-octadecenoic acid at $266^{\circ} \mathrm{C}$. Chemical coordination with $\mathrm{Fe}$ atoms stabilizes the oleate molecules and increases the decomposition/dissociation temperature of the oleate ligand. The second exothermic transition peak (II) matches with the second step weight loss between $241^{\circ} \mathrm{C}$ and $299^{\circ} \mathrm{C}$, as shown in the TGA profile of $\mathrm{FeOl}-14$ in Fig. 5(b). The mass loss of the second step was $39.4 \%$, thus the first mass change is due to the elimination of free cis-9octadecenoic acid and thermal decomposition of one oleate ligand, while the second mass change from $331^{\circ} \mathrm{C}$ to $400^{\circ} \mathrm{C}$
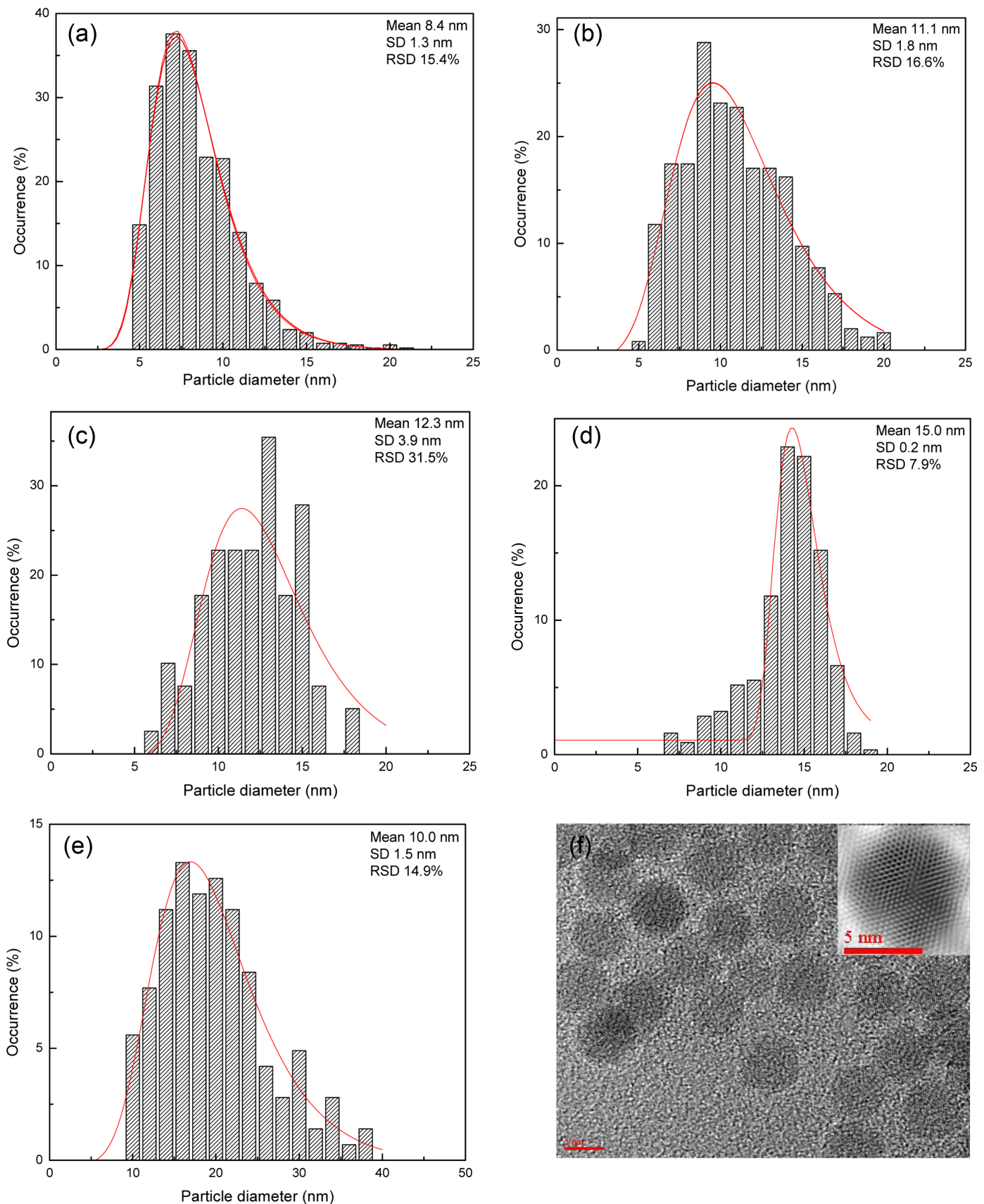

Fig. 6. TEM images (left column) and histograms of particle size distributions (right column) of (a) N1153, (b) N1253, (c) N1353, (d) N1453, and (e) N1553; and (f) high-resolution TEM (HR-TEM) image of N1553, with electron diffraction pattern shown in the inset. (SD means standard deviation, RSD means relative standard deviation). 
is because of the thermal decomposition of the two residual oleate ligands. ${ }^{23}$

The endothermic peak above $300^{\circ} \mathrm{C}$ has previously been attributed to the decomposition of the residual oleate molecules of hydrated $\mathrm{FeOl}$ which causes the particle size to increase. ${ }^{24)}$ In FeOl-12, a very deep transition (III) appeared at $330^{\circ} \mathrm{C}$, and in $\mathrm{FeOl}-13$, the endothermic peak was split into two peaks positioned at $341^{\circ} \mathrm{C}$ (III) and $359^{\circ} \mathrm{C}$ (IV). In FeOl-14, endothermic peaks (III) and (IV) were found at $345^{\circ} \mathrm{C}$ and $349^{\circ} \mathrm{C}$. As the $\mathrm{Fe}(\mathrm{III}) /$ cis-9-octadecenoic acid molar ratio increases, peak (III) is right-shifted and becomes shallower. Correspondingly, in FeOl-14, the remaining weight loss is $34.6 \%$, which can be considered as the formation of iron oxide nanoparticles. The substantial separation between the second (II) and third (III) thermal transition peaks is strong evidence that nucleation and particle growth occur in different stages. Bronstein et al. attributed the peak in the region of $340^{\circ} \mathrm{C}-380^{\circ} \mathrm{C}$ to comprehensive thermal dissociation or restructuring of hydrated $\mathrm{FeOl} .{ }^{20}$ ) Only a shallow endothermic peak (III) was observed at $342^{\circ} \mathrm{C}$ in $\mathrm{FeOl}-15$, and no third endothermic peak was detected.

Particle size distributions calculated with TEM images of N1153 N1553 synthesized with varying molar ratios of Fe(III)/cis-9-octadecenoic acid are shown in Fig. 6(a)-(e). By varying the molar ratio of $\mathrm{Fe}$ (III)/cis-9-octadecenoic acid from $1 / 1$ to $1 / 5$, the diameter of the resulting nanocrystals can be tuned at a fixed reaction temperature $\left(320^{\circ} \mathrm{C}\right)$ and time (30 min). Nanocrystalline iron oxide particles with average diameters of $8.4 \mathrm{~nm}, 11.1 \mathrm{~nm}, 12.3 \mathrm{~nm}, 15.0 \mathrm{~nm}$, and $10.0 \mathrm{~nm}$ were fabricated in ODE. The particle size could be increased by increasing the ratio of $\mathrm{Fe}(\mathrm{III}) /$ cis-9octadecenoic acid from $1 / 1$ to $1 / 4$. Interestingly the particle size starts to decrease when the molar ratio is further raised to $1 / 5$. During particle formation, a lower amount of carboxylic acid compared to metal results in more asymmetrical size distribution and morphology. The particle diameter continuously increased when the molar ratio of cis-9-octadecenoic acid was increased to 4 , but the particle diameter started to decrease afterward. When free cis-9octadecenoic acid exists during particle formation, the free carboxylate acids will be attached on the surface of the nucleated particles and react again with iron ions as a reverse reaction. As a result, iron (III) oleate starts to leach out into the solution.

FTIR spectra of N1553 from a wavenumber of $4,000 \mathrm{~cm}^{-1}$ to $500 \mathrm{~cm}^{-1}$ are shown in Fig. 7. Two strong peaks at 2,925 and $2,852 \mathrm{~cm}^{-1}$ can be assigned to symmetrical and asymmetrical $-\mathrm{CH}_{2}$ stretching. ${ }^{25,26)}$ Two bands appearing at $1,737 \mathrm{~cm}^{-1}$ and $1,711 \mathrm{~cm}^{-1}$ can be attributed to $\mathrm{C}=\mathrm{O}$ stretching vibrations of monomer and dimer cis-9-octadecenoic acid, respectively. ${ }^{27)}$ No significant stretching of $\mathrm{C}=\mathrm{C}$ from cis-9-octadecenoic acid could be distinguished at $1,656 \mathrm{~cm}^{-1}$, possibly due to interference from the $1,711 \mathrm{~cm}^{-1}$ peak. ${ }^{28)}$ The peak at $1,570 \mathrm{~cm}^{-1}$ was attributed to asymmetrical vibration of carboxylate. The $1,455 \mathrm{~cm}^{-1}$ can be attributed

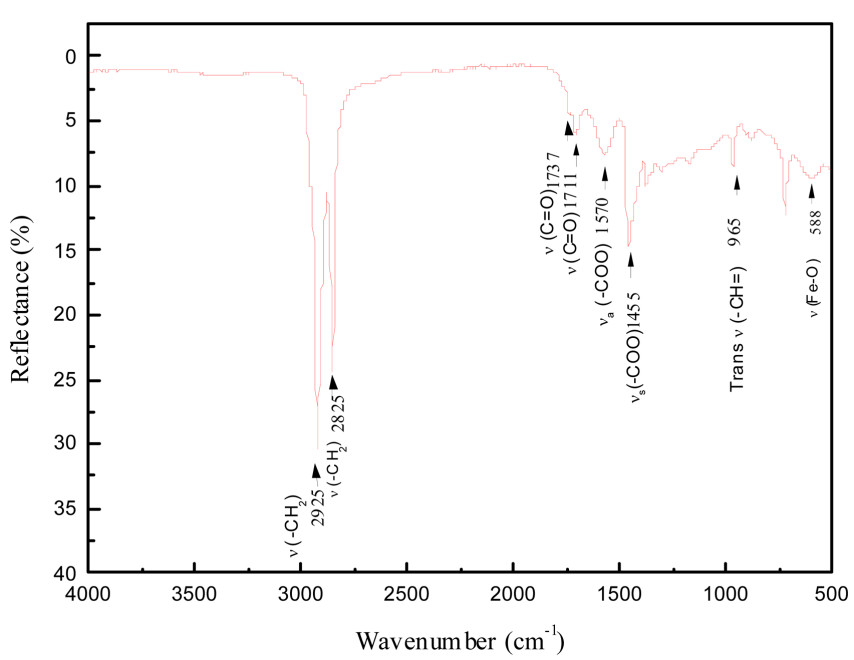

Fig. 7. FTIR spectra of OA-SPIONs (N1553) from wavenumber $4,000 \mathrm{~cm}^{-1}$ to $500 \mathrm{~cm}^{-1}$.

to the symmetrical vibration of carboxylate. ${ }^{27,29)}$ Hence based on the classification of coordination modes by determining the $\Delta$ value $\left(\Delta=115 \mathrm{~cm}^{-1}\right.$, in this case), we conclude that cis-9-octadecenoic acid binds to the surface of iron oxide in a bridging mode. A weak peak was detected at 588 $\mathrm{cm}^{-1}$ due to $\mathrm{Fe}-\mathrm{O}$ bonding; nevertheless, the intensity of this peak is quite low and difficult to distinguish, probably because the surfaces of the particles are fully coated with cis-9-octadecenoic acid.

Figure 8 shows the TGA, DSC, and DTA profiles of $\mathrm{N} 1553$ between $30^{\circ} \mathrm{C}$ and $600^{\circ} \mathrm{C}$ with a heating rate of $10^{\circ} \mathrm{C} /$ min. The first endothermic transition (I) started around $100^{\circ} \mathrm{C}$ and the endothermic peak appeared at $160^{\circ} \mathrm{C}$ in both the DSC and DTA profiles. Correspondingly, the weight loss over the temperature range from $100^{\circ} \mathrm{C}$ to $300^{\circ} \mathrm{C}$ is $\sim 2.2 \%$, which is possibly caused by the evaporation of residual ethanol from the wash cycles or absorbed water.

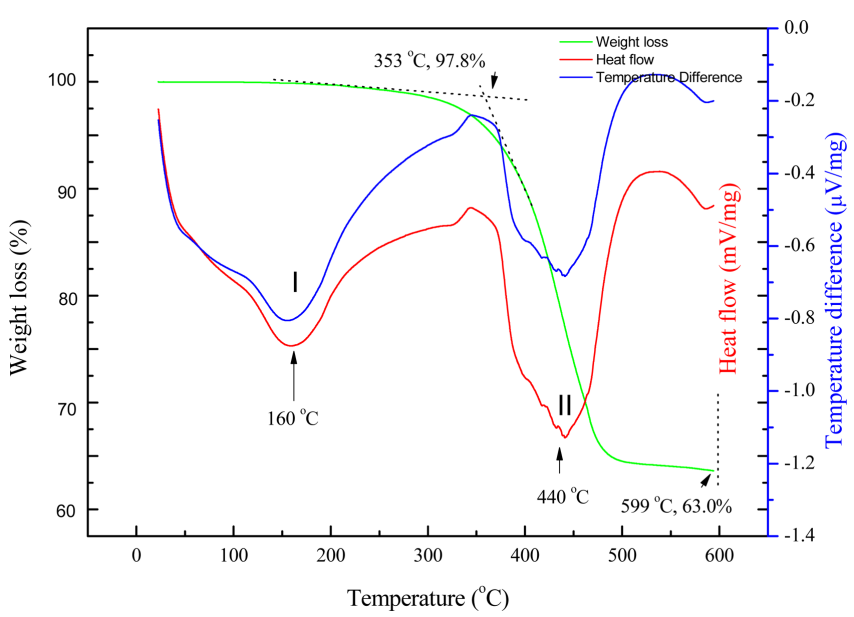

Fig. 8. TGA/DSC/DTA profiles of OA-SPIONs (N1553) as a function from $30^{\circ} \mathrm{C}$ to $600^{\circ} \mathrm{C}$, with a heating rate of $10^{\circ} \mathrm{C} / \mathrm{mL}$ and $\mathrm{N}_{2}$ protection gas at flow rate of 100 $\mathrm{mL} / \mathrm{min}$. 
The second endothermic transition peak (II) appeared at $440^{\circ} \mathrm{C}$ in the DSC and DTA curves, corresponding to a major weight loss of $34.8 \%$ in the TGA profile, which is attributed to the adsorption and decomposition of cis-9-octadecenoic acid molecules. The mass of the remaining inorganic materials was determined to be $63.0 \%$ at $600^{\circ} \mathrm{C}$. Therefore, the observed mass ratio of surfactant cis-9-octadecenoic acid molecules to the inorganic cores $\left(R_{0}\right)$ can be calculated:

$$
R_{0}=\frac{m_{I I}}{m_{r}}
$$

Where $m_{I I}$ is the weight loss percentage of second transition and $m_{r}$ is the remaining weight percentage at $600^{\circ} \mathrm{C}$.

According to the TGA profile shown in Fig. 8,

$$
R_{o}=\frac{97.8 \%-63 \%}{63 \%} \approx 0.552
$$

To compare the observed mass and the theoretical value of the mass ratio of cis-9-octadecenoic acid molecules to the inorganic cores, we calculated the mass ratio of cis-9-octadecenoic acid molecules that absorbed on one single nanoparticle and that nanoparticle itself $(\mathrm{R})$ :

$$
R=\frac{m_{s}}{m_{N P}}
$$

Where $m_{s}$ is the mass of all the surfactant cis-9-octadecenoic acid absorbed on a single nanoparticle and $m_{N P}$ is the mass of the nanoparticle.

Assuming 100\% coverage of the nanoparticle surface, we can calculate the number of the cis-9-octadecenoic acid molecules absorbed on the surface of a nanoparticle $\left(n_{s}\right)$ :

$$
n_{s}=\frac{A_{N P}}{A_{s}}=\frac{4 \pi \cdot r^{2}}{A_{s}}
$$

Where $A_{N P}$ is the surface area of the nanoparticle, $A_{s}$ is the molecular area of the carboxylate group of cis-9-octadecenoic acid on the iron oxide surface, and $r$ is the radius of the given nanoparticle.

Hence, the mass of all the surfactant cis-9-octadecenoic acid absorbed on single nanoparticle $\left(m_{s}\right)$ can be calculated:

$$
m_{s}=\frac{n_{s} \cdot M_{w}}{N_{A}}=4 \pi \cdot r^{2} \frac{M_{w}}{A_{s} N_{A}}
$$

Where $M_{w}$ is the molecular weight of a cis-9-octadecenoic acid molecule and $N_{A}$ is Avogadro's number.

And the mass of a single iron oxide nanoparticle $\left(m_{N P}\right)$ can be calculated:

$$
m_{N P}=\rho \cdot V_{N P}=\rho \cdot \frac{4}{3} \pi \cdot r^{3}
$$

Where $\rho$ is the density of iron oxide.

Therefore, we can calculate the mass ratio of surface absorbed cis-9-octadecenoic acid molecules and the iron oxide core of an individual nanoparticle of an average diameter $(d)$ of $10.0 \mathrm{~nm}$ :

$$
R=\frac{m_{s}}{m_{N P}}=\frac{n_{s} M_{w} / N_{A}}{\rho V_{N P}}=\frac{\frac{A_{N P}}{A_{s}} \cdot \frac{M_{w}}{N_{A}}}{\rho \cdot \frac{4}{3} \pi \cdot r^{3}}=\frac{4 \pi \cdot r^{2} \frac{M_{w}}{A_{s} N_{A}}}{\frac{4}{3} \pi \cdot \rho \cdot r^{3}}
$$

To simply the whole equation:

$$
R=\frac{3 M_{w}}{N_{A} A_{s} \cdot r \cdot \rho}
$$

Klokkenburg et al. reported a density of 3.5 molecules per $\mathrm{nm}^{2}$ on the iron oxide surface, which corresponds to the area of the carboxylate head group of cis-9-octadecenoic acid $\left(0.28 \mathrm{~nm}^{2}\right) .{ }^{30)}$ Rogan et al. estimated the molecular area of the carboxylate group of cis-9-octadecenoic acid on several mineral surfaces to be $\sim 20 \AA^{2}{ }^{31)}$ Yoshida et al. studied several lipid monolayers at the water-oil interface and reported the head group of stearic acid, which has a structure closely related to that of cis-9-octadecenoic acid, occupied an area of $22.5 \AA^{2}$ at the interface. ${ }^{32)}$ In our case, we assumed the molecular area of the carboxylate group of cis9-octadecenoic acid absorbed on the iron oxide surface to be $\mathrm{A}_{\mathrm{s}}=0.25 \mathrm{~nm}^{2}\left(25 \AA^{2}\right)$ and $100 \%$ surfactant coverage of the monolayer of surfactant on the surface of the nanoparticles.

Therefore, the theoretical value of the mass ratio of surface absorbed surfactant to iron oxide core was determined to be $\sim 0.215$

$$
R=\frac{3 \times 282.5 \mathrm{~g} \cdot \mathrm{mol}^{-1}}{6.02214179 \times 10^{23} \mathrm{~mol}^{-1} \times 0.25 \mathrm{~nm}^{2} \times 5 \mathrm{~nm} \times 5.242 \mathrm{~g} \cdot \mathrm{cm}^{-3}} \approx 0.215
$$

Surprisingly, the observed value $\left(R_{0}=0.552\right)$ of the mass ratio of surfactant cis-9-octadecenoic acid to inorganic oxide nanoparticle is two times greater than the calculated value $(\mathrm{R}=0.215)$. Zboril et al. proposed two possible chemical reactions between palmitic acid and magnetic nanoparticles, in which the carboxylate head of the inner layer attached to the surface of the magnetic particle and the outer layer palmitic acid interacted with the inner layer surfactant by hydrophobic interactions. ${ }^{33)}$ Klokkenburg et al. reported two endothermic transitions at $260^{\circ} \mathrm{C}$ and $380^{\circ} \mathrm{C}$, respectively. He postulated that there were two binding modes of cis-9-octadecenoic acid to the iron oxide surface on the different crystal facets of the iron oxide nanocrystals; there remained a single layer of surfactant absorbed on the surface of the particle with less than $90 \%$ coverage. ${ }^{30)}$ As only the second endothermic transition that was correlated with the major weight loss of $34.8 \%$ was assigned to desorption and decomposition of cis-9-octadecenoic acid molecules, it is sensible to conclude that cis-9-octadecenoic acid molecules bind to the surface of iron oxide nanoparticles in one coordination mode. As shown previously in the FTIR spectra of N1553, cis-9-octadecenoic acid binds to the surface of iron oxide nanoparticles only in a bridging mode, which is consistent with the TEM and TGA/ DSC/DTA analysis. FTIR data also showed an intense peak at $1,711 \mathrm{~cm}^{-1}$, which is usually attributed to the stretching of $\mathrm{C}=\mathrm{O}$ in dimer cis-9-octadecenoic acid. Therefore, together 
with FTIR, TEM and thermal analysis of N1553, we conclude that instead of forming a surfactant monolayer with full coverage on the surface of the iron oxide nanoparticles, it is possible that cis-9-octadecenoic acid molecules formed a "quasi-double-layer" on the surface of iron oxide. In this case, the inner layer of cis-9-octadecenoic acid will bind to the iron oxide via bridging coordination, and the rest of the cis-9-octadecenoic acid molecules assemble into the outer layer by forming dimer cis-9-octadecenoic acid via hydrophobic interactions between the hydrocarbon tails of the cis-9-octadecenoic acid molecules.

\section{Conclusions}

In this work, we developed a simple and eco-friendly technique to produce non-hydrate $\mathrm{FeOl}$ complexes which were used in a one-pot reaction to prepare highly monodispersed SPIONs with tunable size. Potential coordination modes of intermediate non-hydrated $\mathrm{FeOl}$ complexes were proposed based on thermal analysis and FTIR data. As shown in the FTIR spectra of SPIONs, cis-9-octadecenoic acid binds on the surface of SPIONs in a bridging mode only, which is consistent with the TEM and TGA/DSC/DTA analysis. We concluded that instead of forming a surfactant monolayer with full coverage on the surface of the SPIONs, it is possible that OA molecules form a "quasi-double-layer" on the surface of SPIONs. Nanocrystalline SPIONs with average diameters $8.4 \mathrm{~nm}, 11.1 \mathrm{~nm}, 12.3 \mathrm{~nm}, 15.0 \mathrm{~nm}$, and $10.0 \mathrm{~nm}$ were fabricated in ODE. The particle size could be increased by increasing the ratio of $\mathrm{Fe}(\mathrm{III}) / \mathrm{OA}$ from $1 / 1$ to $1 / 4$, but was found to decrease after further increasing the ratio of $\mathrm{Fe}(\mathrm{III}) / \mathrm{OA}$ to $1 / 5$.

\section{Acknowledgments}

This research is financially supported by Basic Science Research Program through the National Research Foundation of Korea (NRF) funded by the Ministry of Education, Science and Technology (Grant No. NRF-2017R1A2B4005167).

\section{REFERENCES}

1. S. Kulkarni, B. Ramaswamy, E. Horton, S. Gangapuram, A. Nacev, D. Depireux, M. Shimoji, and B. Shapiro, "Quantifying the Motion of Magnetic Particles in Excised Tissue: Effect of Particle Properties and Applied Magnetic Field," J. Magn. Magn. Mater., 393 243-52 (2015).

2. C. Oka, K. Ushimaru, N. Horiishi, T. Tsuge, and Y. Kitamoto, "Core-Shell Composite Particles Composed of Biodegradable Polymer Particles and Magnetic Iron Oxide Nanoparticles for Targeted Drug Delivery," J. Magn. Magn. Mater., 381 278-84 (2015).

3. P.-E. Le Renard, O. Jordan, A. Faes, A. Petri-Fink, H. Hofmann, D. Rüfenacht, F. Bosman, F. Buchegger, and E. Doelker, "The in vivo Performance of Magnetic ParticleLoaded Injectable, in situ Gelling, Carriers for the Delivery of Local Hyperthermia," Biomaterials, 31 [4] 691-705
(2010).

4. S. Meier, G. Pütz, U. Massing, C. E. Hagemeyer, D. von Elverfeldt, M. Meißner, K. Ardipradja, S. Barnert, K. Peter, C. Bode, R. Schubert, and C. von zur Muhlen, "Immuno-Magnetoliposomes Targeting Activated Platelets as a Potentially Human-Compatible MRI Contrast Agent for Targeting Atherothrombosis," Biomaterials, 53 137-48 (2015).

5. N. Sattarahmady, T. Zare, A. R. Mehdizadeh, N. Azarpira, M. Heidari, M. Lotfi, and H. Heli, "Dextrin-Coated Zinc Substituted Cobalt-Ferrite Nanoparticles as an MRI Contrast Agent: In vitro and in vivo Imaging Studies," Colloids Surf., B, 129 15-20 (2015).

6. G. Mehrnaz, "Synthesis of Magnetic Nanoparticles of Cobalt and Nickel Modified Iron Oxides by Thermal Decomposition of Metal-Carbonyl for Biomedical and Biochemical Applications," Clin. Biochem., 44 [13] S213 (2011).

7. R. S. Sapieszko and E. Matijević, "Preparation of WellDefined Colloidal Particles by Thermal Decomposition of Metal Chelates. I. Iron Oxides," J. Colloid Interface Sci., 74 [2] 405-22 (1980).

8. F. Chen, S. Xie, J. Zhang, and R. Liu, "Synthesis of Spherical $\mathrm{Fe}_{3} \mathrm{O}_{4}$ Magnetic Nanoparticles by Co-Precipitation in Choline Chloride/Urea Deep Eutectic Solvent," Mater. Lett., 112 177-79 (2013).

9. H. Gu, X. Tang, R. Y. Hong, W. G. Feng, H. D. Xie, D. X. Chen, and D. Badami, "Ubbelohde Viscometer Measurement of Water-Based $\mathrm{Fe}_{3} \mathrm{O}_{4}$ Magnetic Fluid Prepared by Coprecipitation," J. Magn. Magn. Mater., 348 88-92 (2013).

10. J. Liang, N. Du, S. Song, and W. Hou, "Magnetic Demulsification of Diluted Crude Oil-in-Water Nanoemulsions Using Oleic Acid-Coated Magnetite Nanoparticles," Colloids Surf., A, 466 197-202 (2015).

11. E. Baeuerlein and D. Schueler, "Biomineralisation: Iron Transport and Magnetite Crystal Formation of Magnetospirillum Gryphiswaldense," J. Inorg. Biochem., 59 [2-3] 107 (1995).

12. V. de Castro, G. Benito, S. Hurst, C. J. Serna, M. P. Morales, and S. Veintemillas-Verdaguer, "One Step Production of Magnetic Nanoparticle Films by Laser Pyrolysis Inside a Chemical Vapour Deposition Reactor," Thin Solid Films, 519 [22] 7677-82 (2011).

13. Y.-Q. Ke, C.-C. Hu, X.-D. Jiang, Z.-J. Yang, H.-W. Zhang, H.-M. Ji, L.-Y. Zhou, Y.-Q. Cai, L.-S. Qin, and R.-X. Xu, "In vivo Magnetic Resonance Tracking of Feridex-Labeled Bone Marrow-Derived Neural Stem Cells after Autologous Transplantation in Rhesus Monkey," J. Neurosci. Methods, 179 [1] 45-50 (2009).

14. K. O'Grady and A. Bradbury, "Particle Size Analysis in Ferrofluid," J. Magn. Magn. Mater., 39 91-4 (1983).

15. N. Shukla, C. Liu, P. M. Jones, and D. Weller, "FTIR Study of Surfactant Bonding to FePt Nanoparticles," J. Magn. Magn. Mater., 266 178-84 (2003).

16. L. Zhang, R. He, and H.-C. Gu, "Oleic Acid Coating on the Monodisperse Magnetite Nanoparticles," Appl. Surf. Sci., 253 2611-17 (2006).

17. L. M. Bronstein, X. Huang, J. Retrum, A. Schmucker, M. Pink, B. D. Stein, and B. Dragnea, "Influence of Iron 
Oleate Complex Structure on Iron Oxide Nanoparticle Formation," Chem. Mater., 19 [15] 3624-32 (2007).

18. M. M. Mossoba, M. P. Yurawecz, P. Delmonte, and J. K. G. Kramer, "Overview of Infrared Methodologies for trans Fat Determination," J. AOAC. Int., 87 [2] 540-44 (2004).

19. T. Hyeon, S. S. Lee, J. Park, Y. Chung, and H. B. Na, "Synthesis of Highly Crystallline and Monodisperse Maghemite Nanocrystallites without a Size-Selection Process," J. Am. Chem. Soc., 123 12798-801 (2001).

20. L. M. Bronstein, X. Huang, J. Retrum, A. Schmucker, M. Pink, B. D. Stein, and B. Dragnea, "Influence of Iron Oleate Complex Structure on Iron Oxide Nanoparticle Formation," Chem. Mater., 19 [15] 3624-32 (2007).

21. M. Lanzon and P. A. Garcia-Ruiz, "Effectiveness and Durability Evaluation of Rendering Mortars Made with Metallic Soaps and Powered Silicons," Constr. Build. Mater., 22 [12] 2308-15 (2008).

22. S. G. Kwon, Y. Piao, J. Park, S. Angappane, Y. Jo, N.-M. Hwang, J.-G. Park, and T. Hyeon, "Kinetics of Monodispersed Iron Oxide Nanocrystals Formation by "Heatingup" Process," J. Am. Chem. Soc., 129 [41] 12571-84 (2007).

23. J. Park, K. An, Y. Hwang, J.-G. Park, H.-J. Noh, J.-Y. Kim, J.-H. Park, N.-M. Hwang, and T. Hyeon, "UltraLarge-Scale Synthesis of Monodisperse Nanocrystals," Nat. Mater., 3 891-95 (2004).

24. A. Shavel, B. Rodriuez-Gonzalez, J. Pacifico, M. Spavosa, M. Farle, and L. M. Liz-Marzan, "Shape Control in Iron Oxide Nanocrystals Synthesis, Induced by Trioctylammonium Ions," Chem. Mater., 21 1326-32 (2009).

25. H. Zeng, P. M. Rice, S. X. Wang, and S. Sun, "Shape-Controlled Synthesis and Shape-Controlled Texture of $\mathrm{MnFe}_{2} \mathrm{O}_{4}$
Nanoparticles," J. Am. Chem. Soc., 126 11458-59 (2004).

26. Y. Hou, Z. Xu, and S. Sun, "Controlled Synthesis and Chemical Conversions of $\mathrm{FeO}$ Nanoparticles," Angew. Chem. Int. Ed., 46 6329-32 (2007).

27. N. Shukla, C. Liu, P. M. Jones, and D. Weller, "FTIR Study of Surfactant Bonding to FePt Nanoparticles," J. Magn. Magn. Mater., 266 [1-2] 178-84 (2003).

28. A. G. Roca, M. P. Morales, K. O'Grady, and C. J. Serna, "Structural and Magnetic Properties of Uniform Magnetite Nanoparticles Prepared by High Temperature Decomposition of Organic Precursors," Nanotechnology, 17 [11] 2783-88 (2006).

29. S. V. Mahajan and J. H. Dikerson, "Synthesis of Monodisperse sub-3 nm $\mathrm{RE}_{2} \mathrm{O}_{3}$ and $\mathrm{Gd}_{2} \mathrm{O}_{3}$ : $\mathrm{RE}^{3+}$ Nanocrystals," Nanotechnology, 18 [32] 325605-11 (2007).

30. M. Klokkenburg, J. Hilhost, and B. H. Erne, "Surface Analysis of Magnetite Nanoparticles in Cyclohexane Solutions of Oleic Acid and Oleylamine," Vib. Spectrosc., 43 [1] 243-48 (2007).

31. K. R. Rogan, "Adsorption of Oleic Acid and Triolein onto Various Minerals and Surface Treated Minerals," Colloid Polym. Sci., 272 [1] 82-98 (1994).

32. T. Yoshida, Y. Yamamoto, and K. Taga, "Effect of WaterSoluble Alcohol on the Surface Conductance of Lipid Monolayers: Bimodal Action,” J. Phys. Chem. B, 107 319698 (2003).

33. R. Zbroil, A. Bakandritsos, M. Mashlan, V. Tzitzios, P. Dallas, C. Trapalis, and D. Petridis, "One-Step Solid State Synthesis of Capped Gamma- $\mathrm{Fe}_{2} \mathrm{O}_{3}$ Nanocrystallites," Nanotechnology, 19 [9] 095602-10 (2008). 